\title{
O FESTIVAL RELIGIOSO RATHA YATRA DESFILA NO ESPAÇO PÚBLICO DA "LISBOA INTERCULTURAL"1
}

\section{DEBORA BALDELLI}

Centro em Rede de Investigação em Antropologia, Faculdade de Ciências Sociais e Humanas, Universidade NOVA de Lisboa, Lisboa, Portugal, 1649-026 - cria@cria.org.pt

列 Universidade NOVA de Lisboa, Lisboa, Portugal, 1069-061 - inet@fcsh.unl.pt
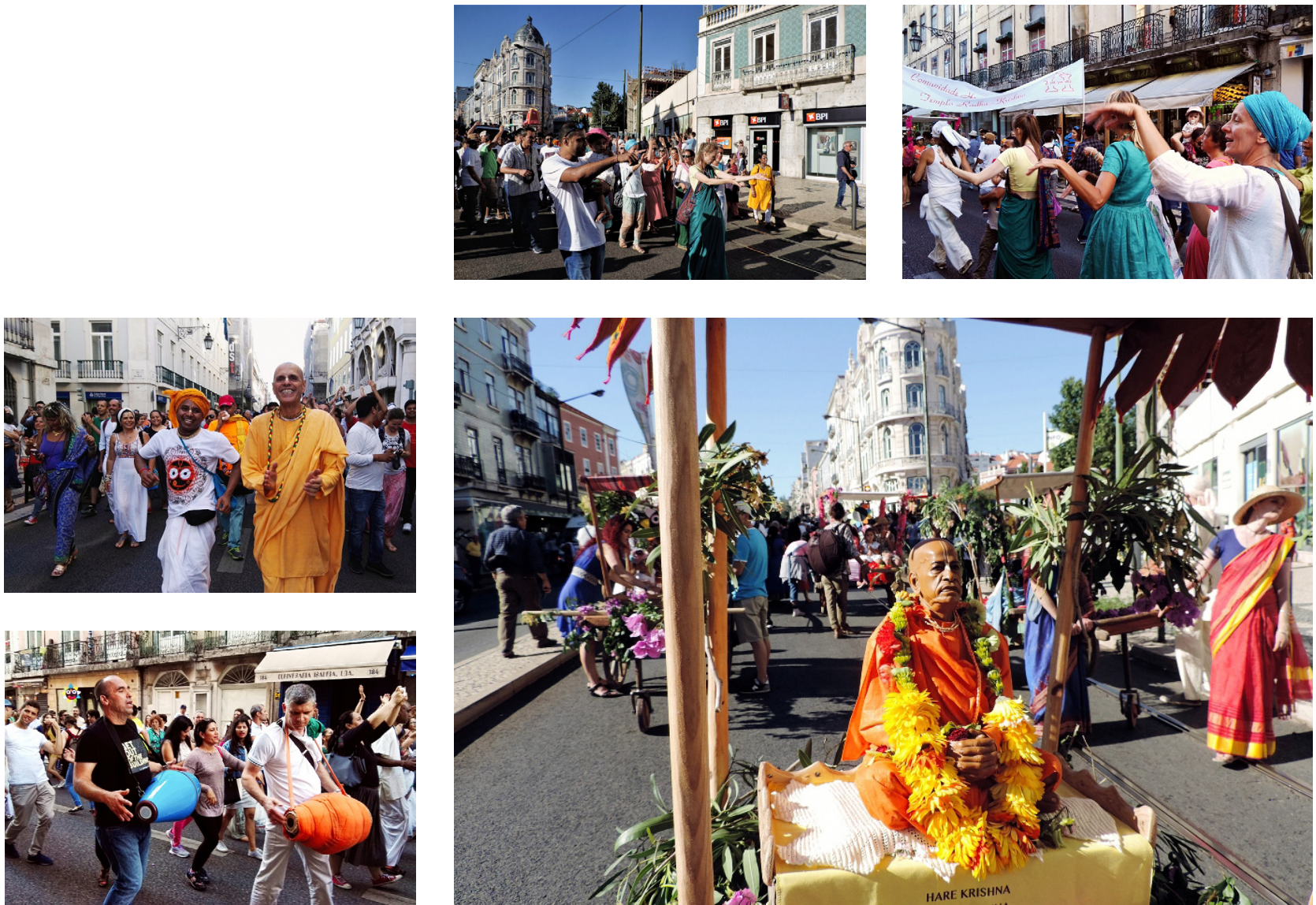

1. Este ensaio fotográfico baseia-se na tese de doutorado da autora, intitulada "Práticas espirituais e expressivas no contexto migratório: uma etnografia do Movimento Hare Krishna na cidade de Lisboa", de 2017, desenvolvida na Universidade Nova de Lisboa, Instituto de Etnomusicologia, e financiada pela Coordenação de Aperfeiçoamento de Pessoal de Nível Superior (Capes, processo 1187-12-0). É uma continuação, de forma independente, por meio do CRIA-FCSH-UNL, da investigação de alguns aspectos desenvolvidos na tese. Agradeço a Inigo Sanchez, Guilherme Tosetto e Fraser Newell pelas sugestões. E-mail: imaginarydebora@gmail.com. Website: http://www.imaginarydebora.com. 
Este ensaio visual acompanha o desfile da segunda edição do festival religioso Ratha Yatra em Lisboa, organizado pelo Movimento Hare Krishna ${ }^{2}$ em 2017. O Ratha Yatra também é conhecido como festival das carruagens, inicialmente comemorado na cidade de Jaganata Puri, na Índia. O Movimento Hare Krishna organiza esse mesmo festival há décadas em várias cidades, como Londres, Paris e Nova York. É a atividade que dá a maior visibilidade ao Movimento Hare Krishna hoje em dia.

O Ratha Yatra Lisboa tem como base a proposta de unir diferentes grupos, entidades e comunidades de imigrantes na sua organização para uma performance coletiva pelas ruas do centro da cidade, realizando uma espécie de desfile de cidadania. Em Lisboa, o festival passa por algumas das principais ruas do centro da cidade, partindo do Largo do Intendente, recentemente gentrificado, passando por alguns dos principais pontos turísticos, como a Praça do Comércio, recentemente renovada, em direção à Ribeira da Naus, localizada na beira do rio Tejo. Ao longo do caminho do Ratha Yatra, o mantra Hare Krishna é cantado e, assim como em um bloco de carnaval, suas letras e melodia são repetidas pela maioria dos que seguem o desfile, proporcionando sentimentos de integração entre os que participam. O Ratha Yatra também deve ser visto como resultado da busca do Movimento Hare Krishna por participar das práticas expressivas da cidade que seguem a "diversidade" e o "multiculturalismo" proposto pela Câmara de Lisboa, visto como uma possibilidade para o seu crescimento.

O Movimento Hare Krishna vem procurando integrar-se às práticas cotidianas e festivas da sociabilidade da cidade de Lisboa, organizando atividades que, apesar de serem de natureza religiosa, são apresentadas como eventos culturais da cidade. As atividades do Movimento Hare Krishna estão alinhadas com a mudança na dinâmica da cidade e com uma política cultural que visa promover a imagem de Lisboa como uma cidade multicultural e cosmopolita e que vem mudando a oferta de serviços, atividades e eventos, incluindo os que têm um aspecto religioso. o Movimento Hare Krishna vem ocupando cada vez mais o espaço festivo da cidade ao tratar a prática espiritual como um espetáculo público (Rasmussen 2010, 125). Os devotos e os participantes das atividades do Movimento Hare Krishna, na sua maioria imigrantes, se apropriam do espaço público para se expressar como cidadãos na cidade onde vivem.

2. Apesar de o Movimento Hare Krishna (ISKCON) ser um ramo do hinduísmo, não foi desenvolvido na Índia. Na verdade, quando a ISKCON (Sociedade Internacional para a Consciência de Krishna) foi registrada nos Estados Unidos, em 1966, seu fundador, Bhaktivedanta Swami Prabhuphada, descreveu a prática como um "movimento espiritual". Em Lisboa, existe um acordo de convivência entre devotos de Krishna e famílias hindus que não são devotas de Krishna. A ISKCON e comunidades hindus tornaram-se mais colaborativas recentemente, uma vez que o Movimento Hare Krishna vem ajudando essas comunidades a ganhar visibilidade na cidade com o Festival Ratha Yatra. 
O aquecimento do desfile acontece no Largo do Intendente. Devotos Hare Krishna e membros de diversas comunidades hindus tocam instrumentos, como a mrindanga (tambor indiano), e cantam mantras para que o público presente se mantenha animado para o início do desfile.

Devotos tocam mrindangas, que são o principal instrumento do desfile, pela sua qualidade rítmica.

Um devoto sopra uma concha, conhecida como shankha, que reproduz o som do Ohm. O som da concha também é usado para chamar a atenção dos presentes para a cerimônia, focando melhor os mantras sendo tocados.
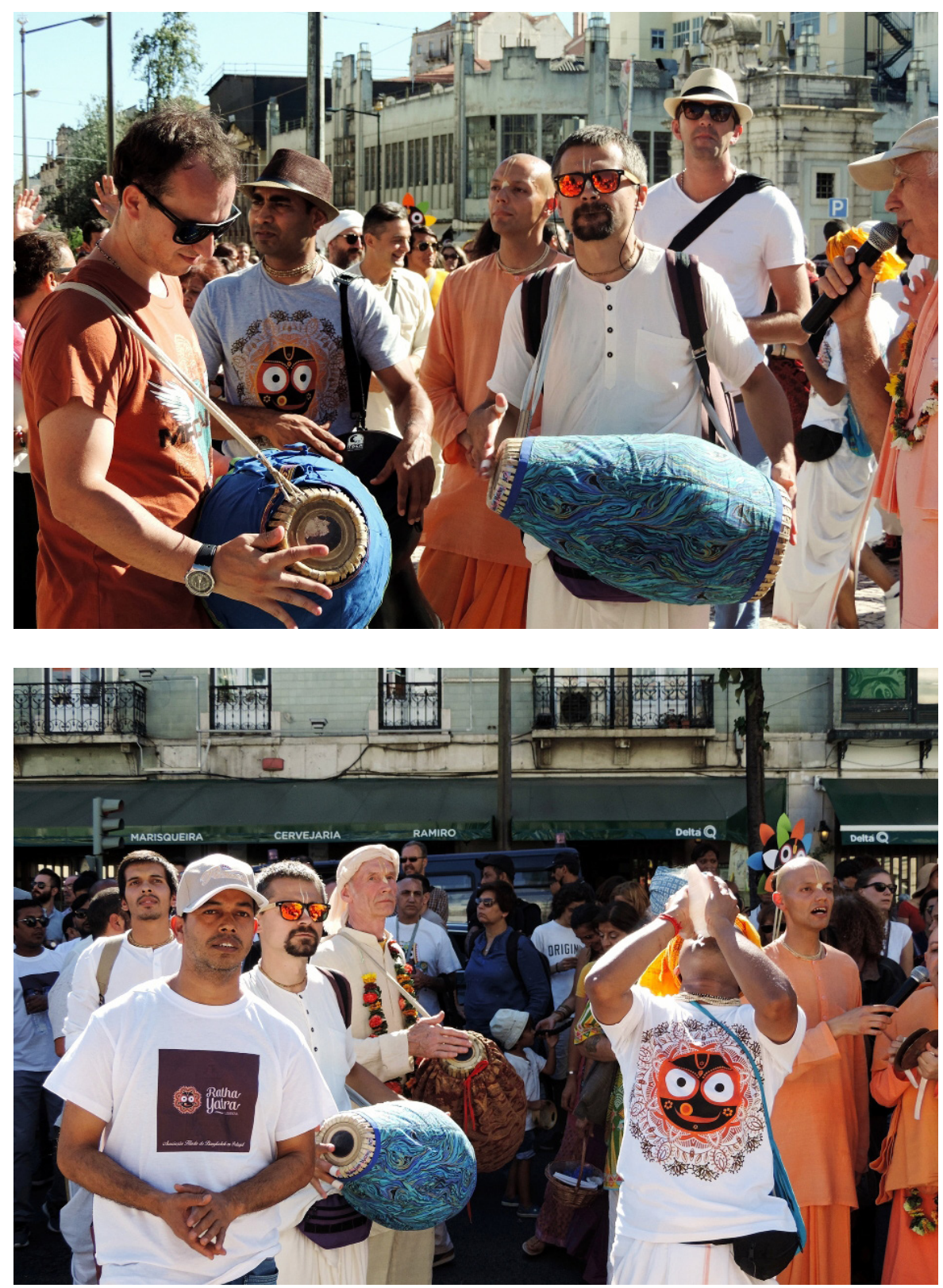
O desfile se inicia com as carruagens à frente, onde se encontram deidades (estátuas religiosas). Entre as deidades, a do fundador do Movimento Hare Krishna, Bakhtivedanta Swami Praphupada, lidera, à frente, o grupo de pequenas carruagens.

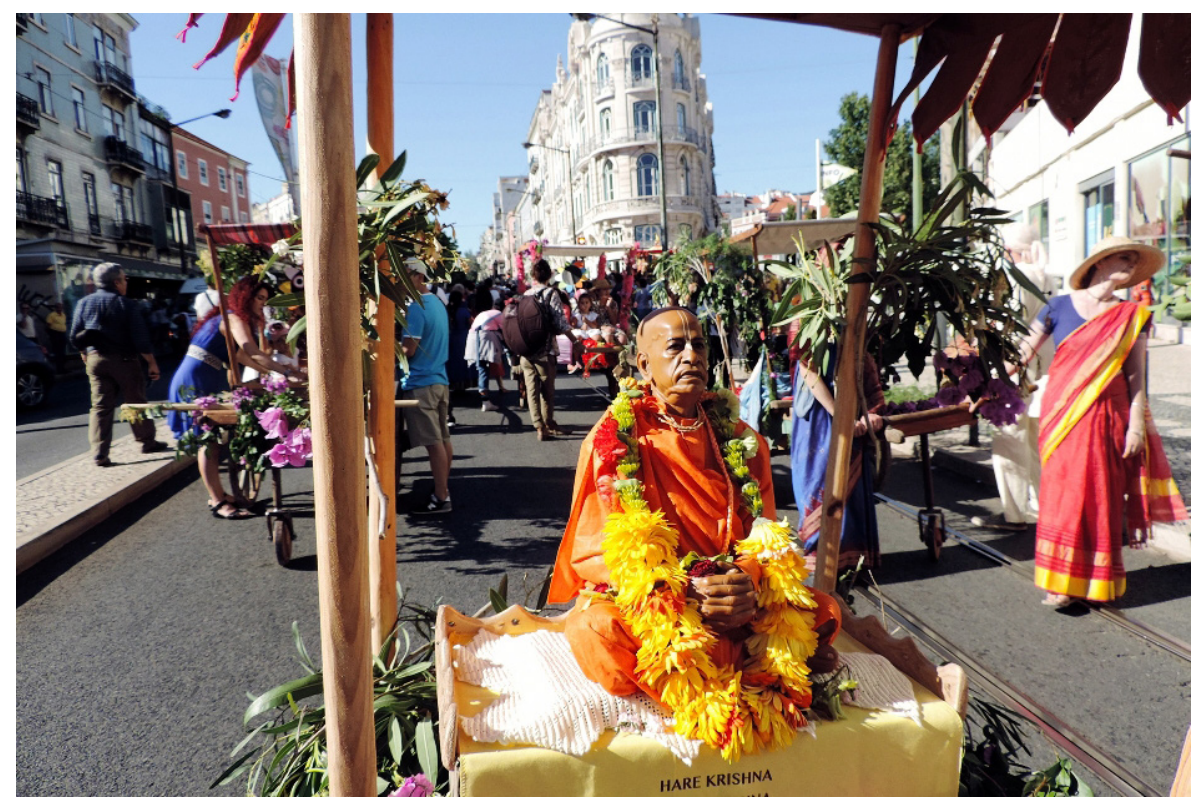

As duas fotos seguintes mostram o grupo que segue atrás das carruagens, a realizar coreografias em busca do engajamento do público presente. Ao fundo é possível ver ainda o Largo do Intendente, um dos pontos mais importantes do processo de gentrificação da cidade de Lisboa, onde o desfile se iniciou.

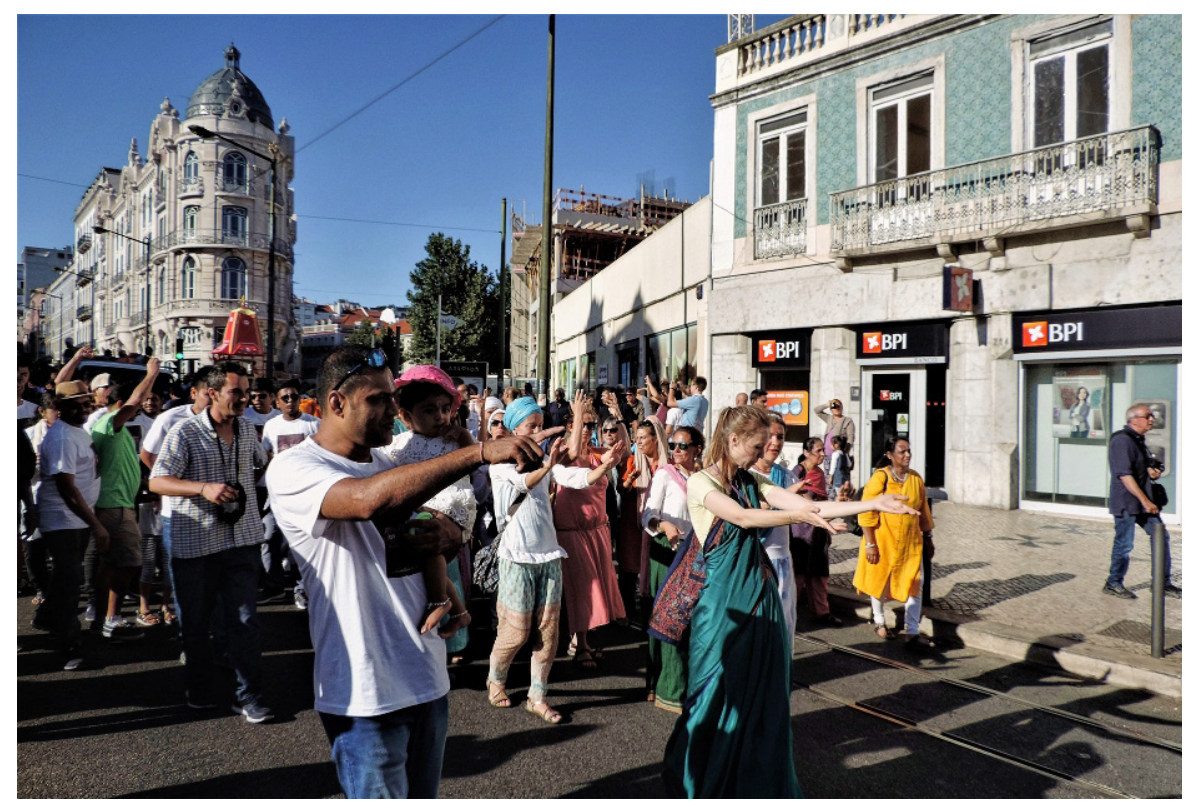




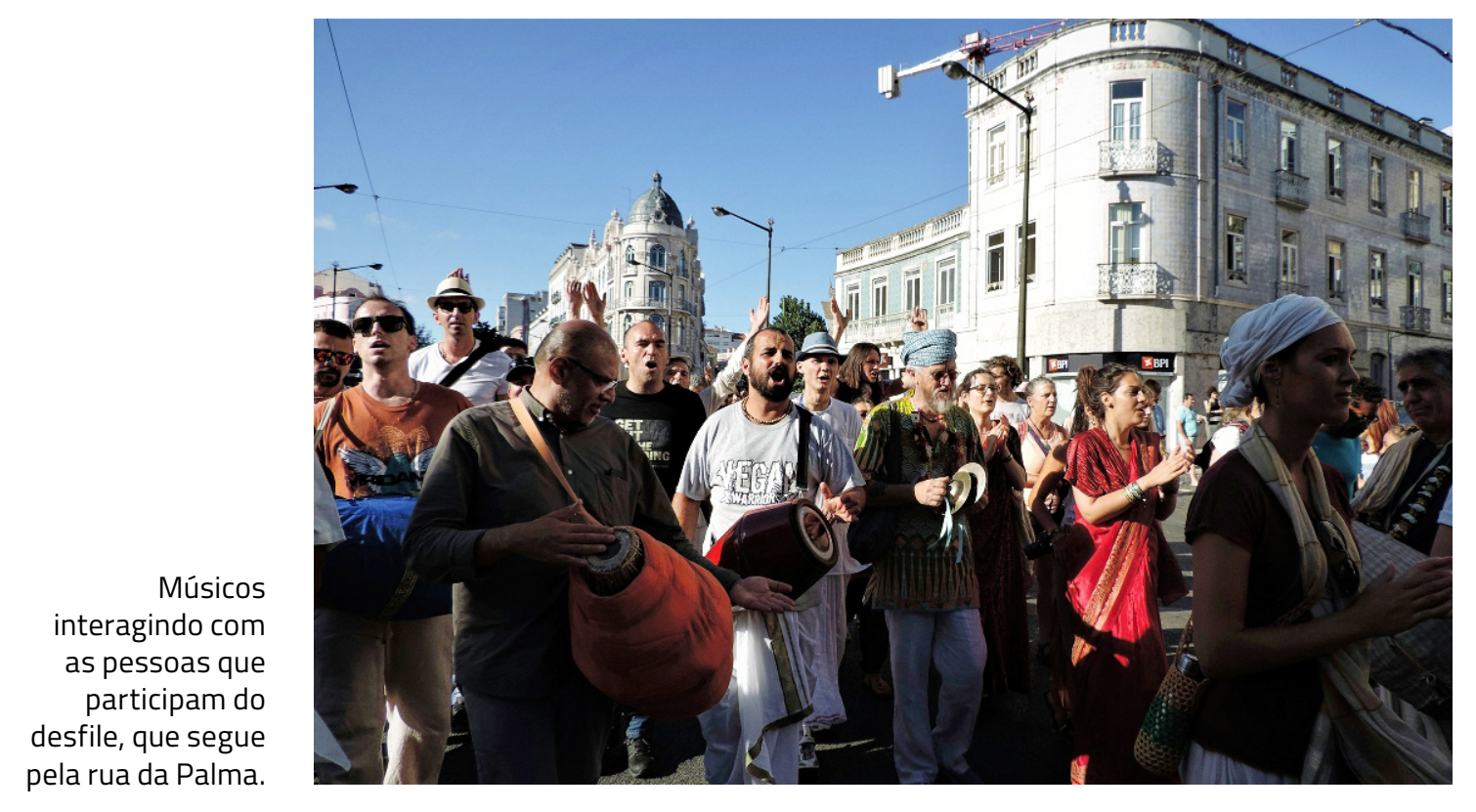

Na foto abaixo, pode-se ver um grupo de imigrantes de Bangladesh, com suas camisetas do festival confeccionadas por eles próprios, desfilando animadamente ao passarem ao lado do Hotel Mundial, na praça Martim Moniz, a caminho da Praça da Figueira.

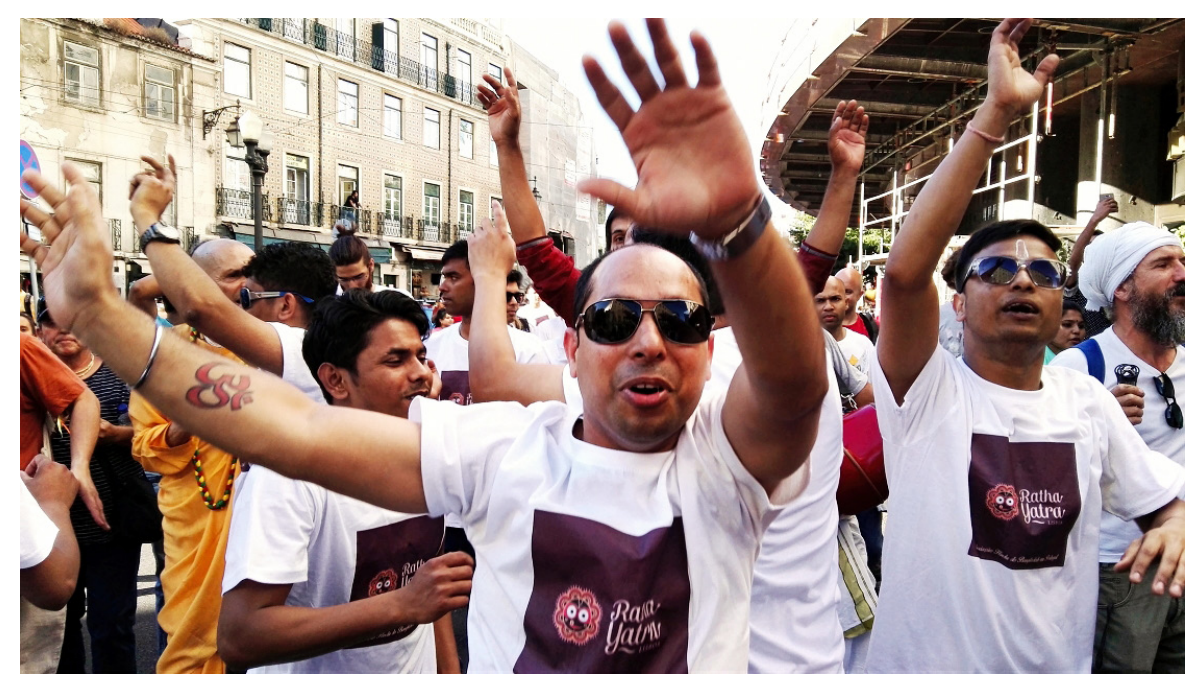

Por não possuir um número expressivo de devotos para fazer um desfile de grande escala, o Ratha Yatra não consegue acontecer em Lisboa sem o apoio das comunidades hindus. o festival, iniciado em 2016 em Lisboa, é uma tentativa do movimento de criar um diálogo com a Câmara Municipal de Lisboa e se concentrou em mostrar o Ratha Yatra e o Movimento Hare Krishna como uma tradição hindu com um bom diálogo com outras comunidades hindus na cidade, como a Comunidade Hindu de 
Portugal, Templo de Shiva, Gurdwara Sikh Sangat Sahib (templo Sikh), BAPS Sri Swaminarayan Mandir, Comunidade Bangladesh em Portugal e Templo de Durga, todas colaboradoras do festival. Embora a maioria das comunidades hindus não esteja interessada em um diálogo aprofundado com os Hare Krishna, o Ratha Yatra cria uma possibilidade de representação hindu por meio da ocupação do espaço público da cidade.

Um grupo de mulheres de

diferentes origens realiza coreografias na rua Aurea, logo atrás da bandeira da Comunidade Hindu de Portugal.

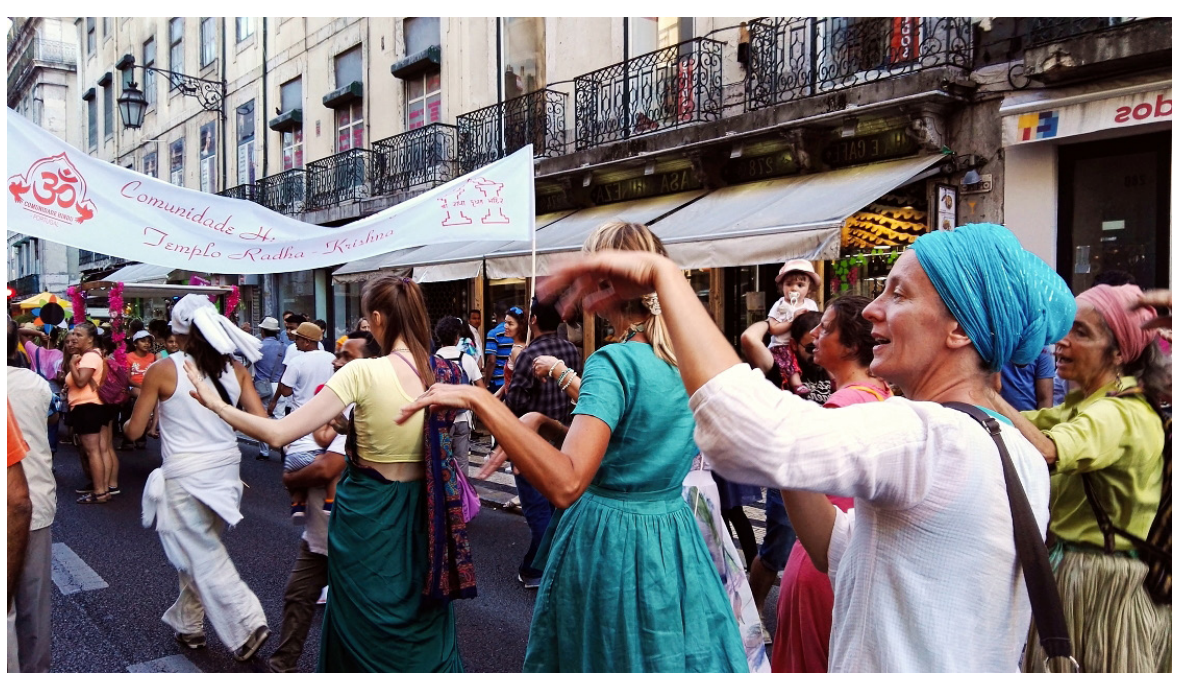

Na edição de 2017 do Festival Ratha Yatra, o diálogo e a representação como um festival que une as comunidades hindus aumentaram perante a Câmara de Lisboa. Foi assinado um protocolo de apoio e co-organização com o legislativo lisboeta, pelo qual se incluiu o festival na programação da "interculturalidade" com os dizeres: "Ratha Yatra é um festival universal feito por todos e para todos".

Na Praça da

Figueira, um grupo de turistas observa o desfile pela varanda.

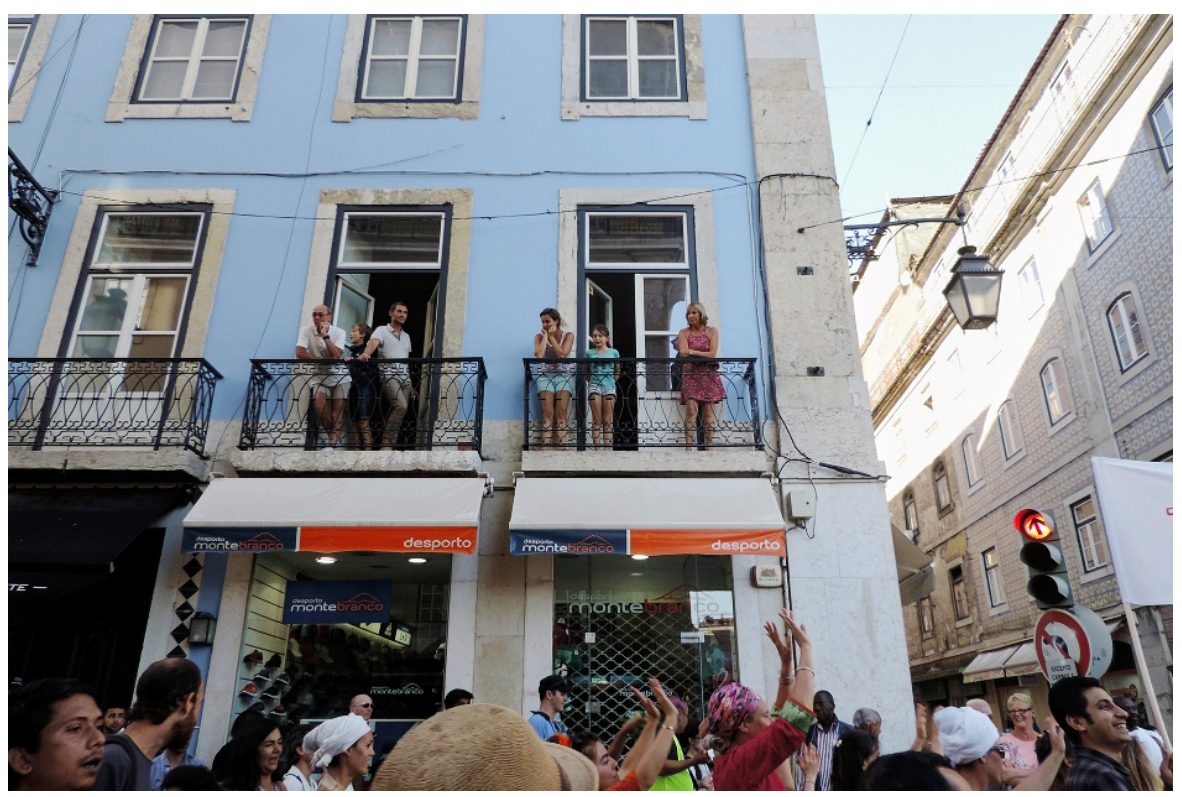


veem-se dois

representantes

da Câmara

Municipal de

Lisboa (em laranja) presentes, mas

não participativos,

passando pelo

grande grupo

de turistas que

assiste ao desfile,

enquanto esperam

sua vez de subir

no elevador de

Santa Justa.

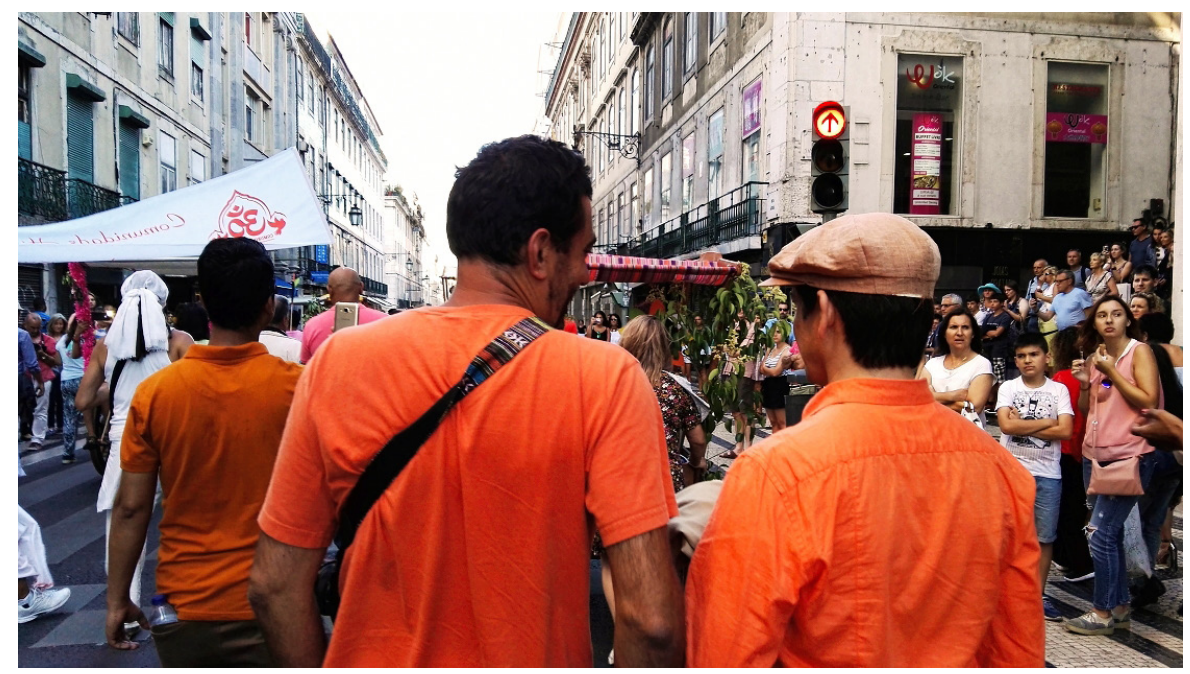

O caráter cosmopolita de Lisboa, juntamente com o processo de turistificação e gentrificação da cidade, mudou as atividades culturais da cidade, o que também influenciou a forma como as práticas espirituais e religiosas funcionam no espaço público. Essa característica cosmopolita permite que práticas religiosas e espirituais, como a dos devotos Hare Krishna, ampliem o seu diálogo com associações culturais de imigrantes, como as relacionadas aos países do Sul Asiático, que buscam maior visibilidade como imigrantes na cidade. A política cultural da Câmara Municipal de Lisboa abre-se para celebrações de todos os tipos, incluindo religiosas. Essas celebrações são apresentadas como atividades culturais da cidade. Práticas expressivas como as realizadas por devotos Hare Krishna começam a participar do processo de festivalização da religião.

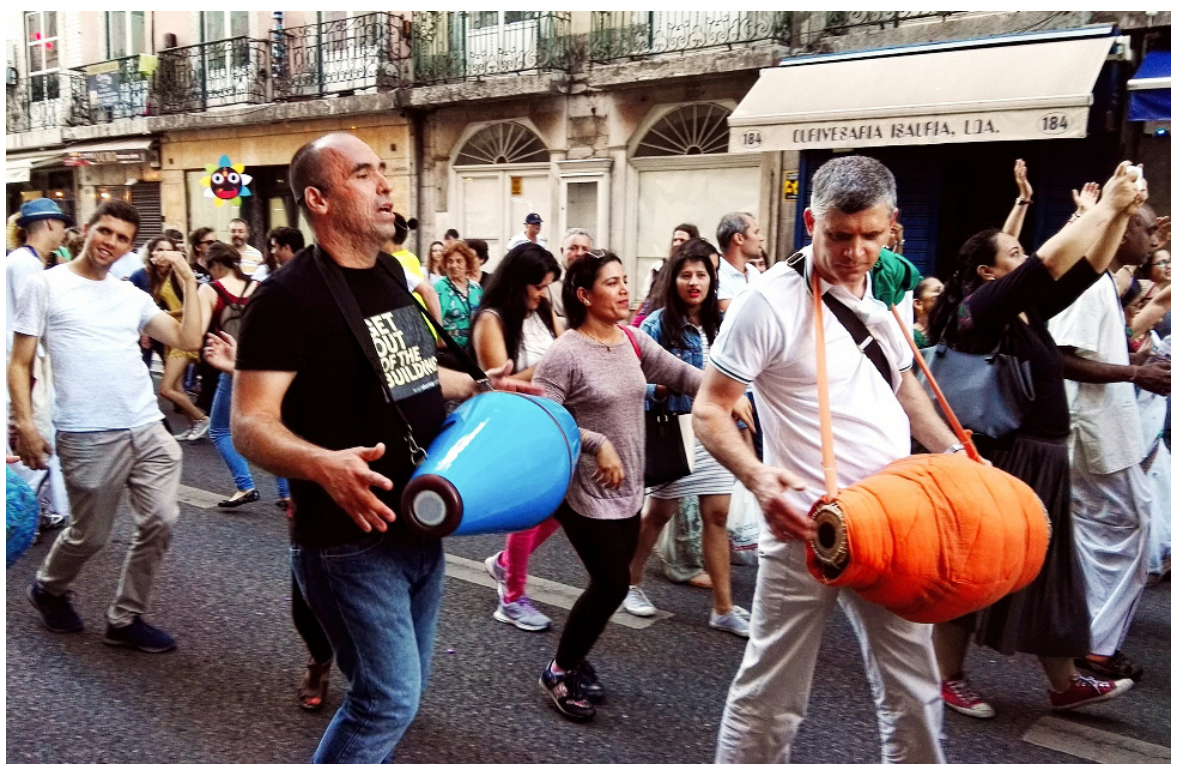

Músicos em meio aos participantes já da metade para o fim do desfile. 


\section{À direita está o principal líder do templo Hare Krishna de Lisboa, Param Gati Praphu, brasileiro, dançando ao lado de um devoto também Hare Krishna de origem indiana, à frente de um grande grupo diverso de pessoas de diferentes origens.}

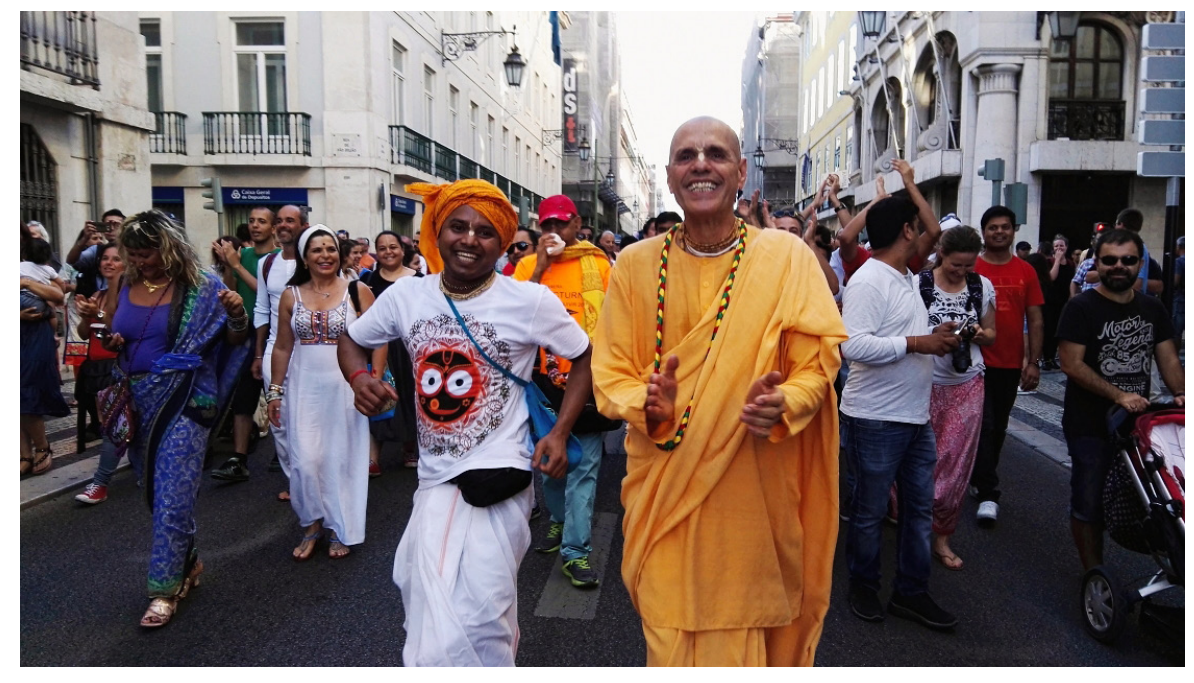

Já no fim do desfile, a foto destaca a bandeira da Comunidade Hindu de Portugal a chegar ao destino final do desfile, onde acontecerão apresentações no "palco da interculturalidade" montado pela Câmara de Lisboa.

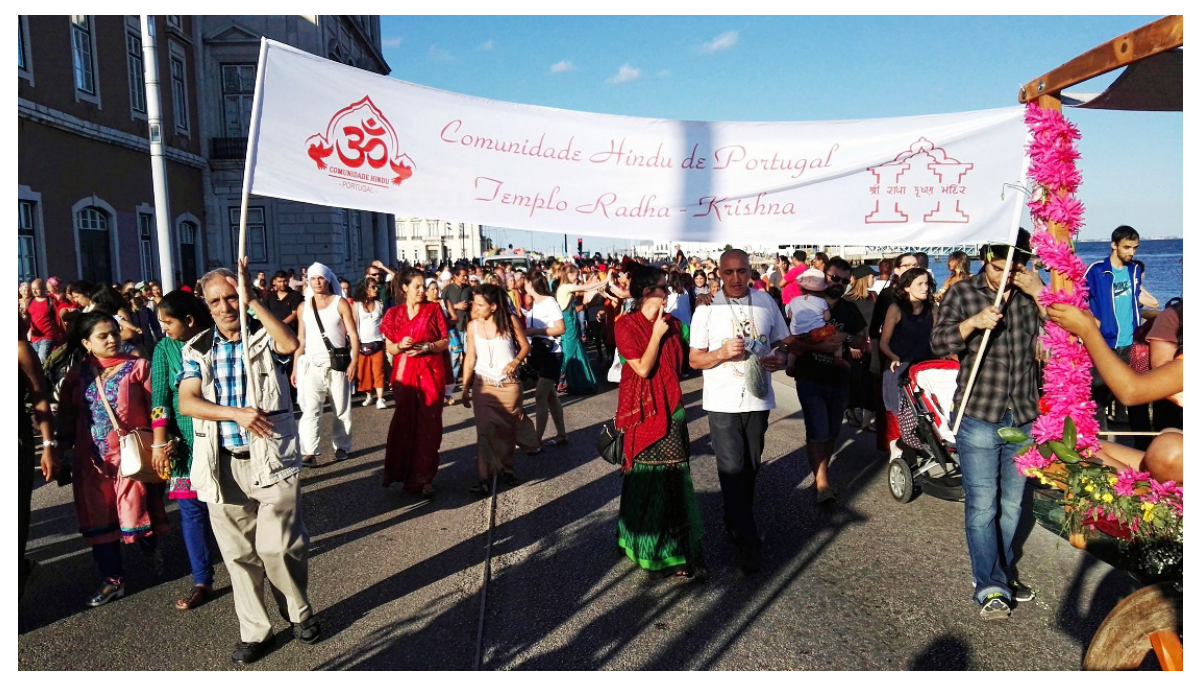

Com essas imagens, procurei ressaltar a importância do desempenho musical, a dança e outras práticas expressivas como formas de indivíduos articularem identidades coletivas fundamentais para a formação e o sustento de grupos sociais, indispensáveis para a sobrevivência (Turino 2008, 2). Procurei também enfatizar a importância das performances associadas à música e à dança no espaço público para a compreensão das experiências transnacionais ((Trovão et al, 2008, 2)). A sua importância também está relacionada com a compreensão das autoidentificações e dos posicionamentos sobre os contextos de origem e os da integração migratória $(2010,11)$, representada neste ensaio pela congregação de devotos imigrantes de diversos grupos religiosos no Festival Ratha Yatra em Lisboa. 


\section{REFERÊNCIAS BIBLIOGRÁFICAS}

Turino, Thomas, 2008, Music as Social Life. University of Chicago Press

Rasmussen, Anne, 2010, Women, the Recited Qur'an, and Islamic Music in Indonesia. University of California Press

Trovão, Susana e Marta Rosales (ed.), 2010. Das Índias - Gentes, Movimentos e Pertenças Transnacionais. Editora Colibri.

\section{RESUMO}

Este ensaio visual acompanha o desfile da segunda edição do festival religioso Ratha Yatra em Lisboa, organizado pela ISKCON Lisboa (Associação Internacional para a Consciência de Krishna) desde 2016. O Ratha Yatra Lisboa tem como base a proposta de unir diferentes grupos, entidades e comunidades de imigrantes na sua organização para uma

PALAVRAS-CHAVE

Religião; festivais; imigração; turistificação; espaço público.

KEYWORDS

Religion; festival; imigration; tourism; public space. performance coletiva pelas ruas do centro da cidade, realizando uma espécie de desfile de cidadania. Procuro enfatizar a importância das performances associadas à música e à dança no espaço público para a compreensão das experiências transnacionais.

\section{ABSTRACT}

This photo essay presents the second edition of the Ratha Yatra religious festival in Lisbon which has been organised by ISKCON Lisbon (International Society for Krishna Consciousness) since 2016. The Ratha Yatra Lisbon proposes to unite different groups, entities and communities of immigrants in a collective performance through the streets of the city centre, performing what could be called a "citizenship parade";. I sought to emphasise the importance of performances associated with music and dance in public spaces to the understanding of transnational experiences.

DEBORA BALDELLI é doutora em etnomusicologia pela Universidade Nova de Lisboa. É colaboradora no CRIA (Centro em Rede de Investigação em Antropologia), na FCSH/ NOVA, e doutora integrada no INED-md (Instituto de Etnomusicologia e Dança), na mesma instituição. Suas investigações centram-se no estudo de práticas expressivas na cidade. E-mail: baldelli@fcsh.unl.pt

Licença de uso. Este artigo está licenciado sob a Licença Creative Commons CC-BY. Com essa licença você pode compartilhar, adaptar, criar para qualquer fim, desde que atribua a autoria da obra. 